\title{
Análisis tipológico del llagar tradicional de sidra en Asturias: aproximación desde la representación gráfica
}

\author{
Estefanía Fernández-Cid Fernández-Viña \\ Universidad Politécnica de Madrid
}

\section{RESUMEN}

El objeto de estudio es la definición del llagar tradicional de sidra en el Principado de Asturias como tipo arquitectónico. El método de investigación se apoya en la aproximación directa y material al bien analizado, para lo que ha sido esencial la herramienta manual del dibujo y el estudio de la representación gráfica de otros autores. Se lleva a cabo desde una perspectiva territorial, funcional y constructiva apoyada en la exposición de los invariantes que caracterizan el tipo y sus adaptaciones. Se realiza, en definitiva, un aporte original de conocimiento en defensa de la conservación y divulgación de estas arquitecturas que están en un claro periodo de obsolescencia por la falta de uso y mantenimiento.

\section{PALABRAS CLAVE}

Llagar tradicional, tipo, arquitectura vernácula productiva, sidra, Asturias

Typological analysis of the traditional cider llagar in Asturias: an approach from graphic representation

\section{ABSTRACT}

The scope of the article is the definition of the traditional cider manufacturing establishements in the Principado de Asturias, llagares, as an architectural type. Direct and material approach to the analyzed asset have supported the research method, for which hand drawing and graphic representation studies from other authors have been essential. A territorial, functional and constructive perspective, supported by the exposition of the invariants that characterize the type and its adaptations has driven the research. In short, an original contribution of knowledge defending the conservation and dissemination of these architectures that are in a clear period of obsolescence due to the lack of use and maintenance.

Traditional llagar, type, productive vernacular architecture, cider, Asturias 
$Y$ entonces no despreciarás ni las cosas más humildes. Gustavo Bueno, 1991

El llagar de sidra tradicional entendido como tipo arquitectónico, se enmarca y acota territorialmente en el ámbito geográfico de la Comarca de la Sidra, comprendida por los concejos de Bimenes, Cabranes, Colunga, Nava, Sariego y Villaviciosa.

El trabajo se desarrolla tras la visita in situ de numerosos llagares que se limitan en número conscientemente ya que "existen en infinidad de caserías asturianas (...) y porque, de forma completa, "la labor de búsqueda de pequeños lagares en funcionamiento sería prácticamente imposible".

Este territorio, enmarcado entre el mar y la montaña, hunde sus raíces comunes en el histórico hilo conductor sociocultural y productivo de la elaboración de sidra asturiana. Esta cultura vinculada a la sidra, forma parte -de uno u otro modo- de la vida de todos los habitantes de este territorio. Por ello, desde el Decreto 64/2014, de 2 de Julio, la Cultura Sidrera Asturiana, está considerada Bien de Interés Cultural de Carácter Inmaterial ${ }^{2}$.

Dentro de este marco cultural tan amplio y transversal a todos los aspectos de una sociedad concreta, uno de los elementos imprescindibles a tener en cuenta -y escasamente estudiado- es el lugar en el que la sidra se fabrica: el edificio.

El espacio arquitectónico en el que la sidra ha sido producida desde sus orígenes se denomina llagar. Estos llagares son arquitecturas humildes, que nacen de la tierra y de los materiales locales, levantadas por un motivo plenamente funcional por aquellos que las utilizaron, son un ejemplo importante de nuestra arquitectura vernácula construida sin arquitectos.

Nos encontramos ante un tipo de arquitectura incluida en el Plan Nacional de Arquitectura Tradicional y que se engloba en la "arquitectura para el trabajo"3. Además, estas construcciones están recogidas en la Ley 1/2001 de Patrimonio

ARAMBURU, Tomás, “Lagares y lagareros”, en El libro de la sidra, Pentalfa, Oviedo, 1991, pp. 361-391.

2 Decreto 64/2014, de 2 de julio, por el que se declara Bien de Interés Cultural de Carácter Inmaterial la Cultura Sidrera Asturiana, Consejería de Educación, Cultura y Deporte del Principado de Asturias. [https://sede. asturias.es/bopa/2014/07/11/2014-12067.pdf]

3 Plan Nacional de Arquitectura Tradicional, Ministerio de Educación Cultura y Deporte - Gobierno de España,
Cultural del Principado de Asturias ${ }^{4}$. A pesar de ello, se observa una escasez importante de protección individualizada en los Catálogos de Protección de los seis concejos de la Comarca de la Sidra.

\section{Sobre la representación gráfica de los llagares}

En proporción a las representaciones gráficas existentes de los llagares tradicionales asturianos son escasos los ejemplos encontrados y, además, casi inexistentes, aquellos que voluntariamente han sido realizados desde el punto de vista arquitectónico, buscando una caracterización explícita e intencionada de dicha arquitectura.

Aparecen representaciones costumbristas de interiores de llagares y de llagares en el paisaje, bien estudiadas por el autor Luis Benito García Álvarez ${ }^{5}$. Una de las obras que recoge este autor es Fiesta de aldea (Fig. 1a), realizada por el destacado pintor asturiano Evaristo Valle; en ella puede observarse en el margen inferior izquierdo a un nutrido grupo de personas a la puerta de un llagar. Cumple este llagar representado con el arquetipo del llagar exento con el portalón en la fachada principal y los demás muros ciegos. Del mismo modo, en dicha obra, en la parte superior, al fondo del pueblo, el autor representa una casa típica asturiana con galería y, adosado a la misma por su izquierda, se localiza un volumen construido, a un solo agua, contra el terreno, que perfectamente podría tratarse de otro llagar.

También podemos encontrar ejemplos gráficos dentro del amplio fondo documental de la Fábrica de Sidra el Gaitero realizados con fines publicitarios (Fig. 1b). Un ejemplo lo encontramos en el libro Valle, Ballina y Fernández S.A. Historia de una empresa ${ }^{6}$, en el que puede observarse como fondo escénico un llagar

Madrid, 2015, p.14, [https://sede.educacion.gob.es/publiventa/d/20699C/19/1]

4 Ley 1/2001 de Patrimonio Cultural de Principado de Asturias.

5 GARCÍA ÁLVAREZ, Luis Benito, Las representaciones de la sidra en la literatura y la pintura asturianas contemporáneas (1850-1939), Ayuntamiento de Gijón, Gijón, 2008.

6 CRABIFFOSSE CUESTA, Francisco, Valle, Ballina $y$ Fernández, S.A. Historia de una empresa, Fundación José Cardín, Villaviciosa, 2010, p. 120. 

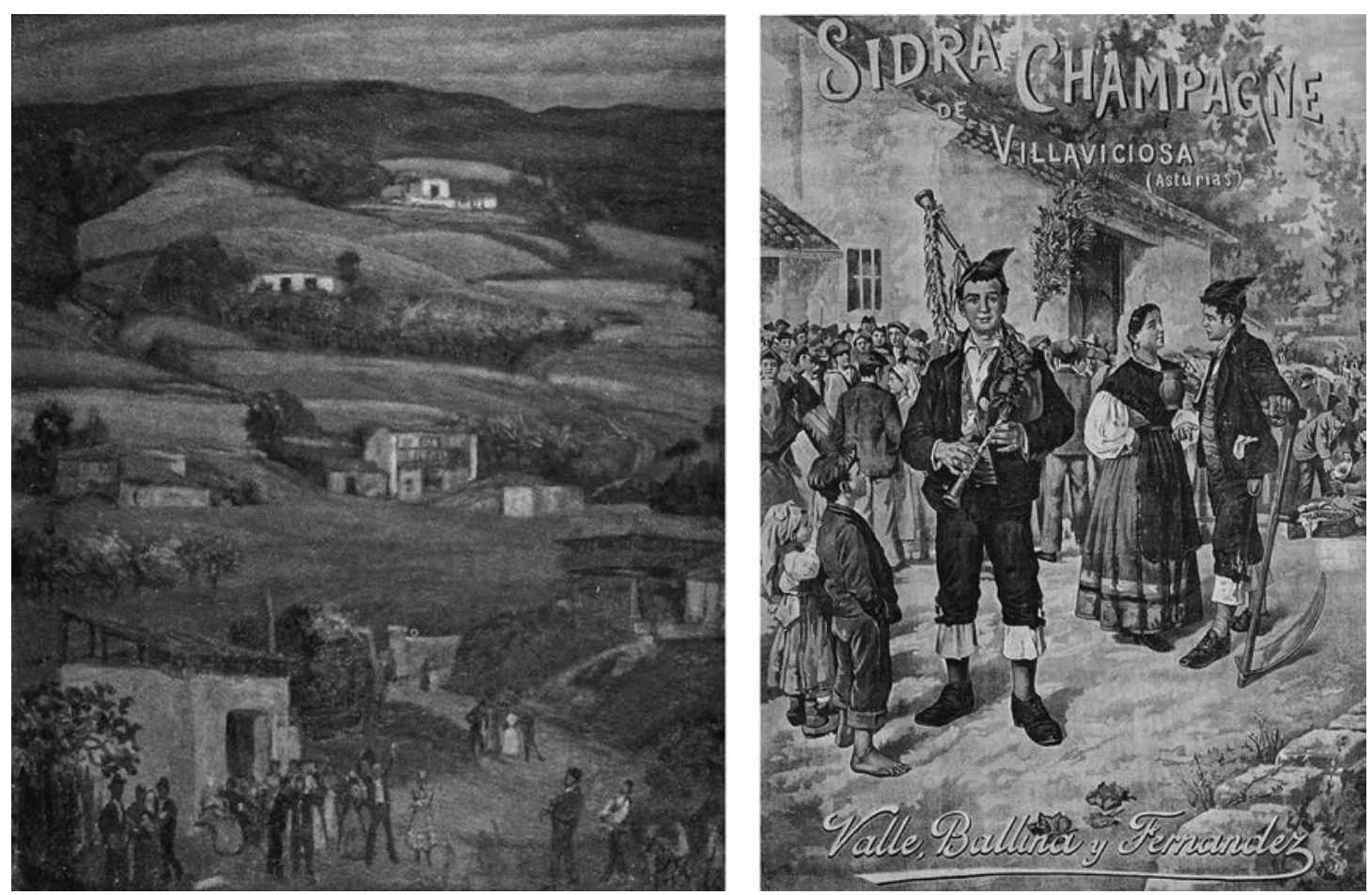

Fig. 1. Composición de imágenes de elaboración propia. Fig. 1a. Evaristo Valle (Gijón, 1873-1951), Fiesta de Aldea, Colección Cajastur. Extraida del libro El contexto social de la sidra a través de la literatura y la pintura asturianas (1850-1939) de Luis Benito García Álvarez, 2008. Fig. 1b. Cartel publicitario de Sidra Champagne El Gaitero, perteneciente a la empresa Valle, Ballina y Fernández. Extraído del libro Valle, Ballina y Fernández. S.A. Historia de una empresa, de Francisco Crabiffosse Cuesta, 2010, p.120.

con portalón en su fachada principal y un ramo de laurel que se colocaba en los llagares como símbolo de celebración de espicha en el interior del edificio. En el centro de la obra se percibe a una mujer, ataviada con el traje tradicional asturiano junto a un hombre que en su mano derecha lleva una jarra. Estas jarras eran las utilizadas en los llagares previo a la aparición de los vasos y botellas de sidra actuales.

Fray Toribio de Santo Tomás y Pumarada escribió, en el s.XVIII, El arte general de Grangerías $^{7}$, donde explicaba cómo construir una granja próspera en la Riera, Asturias. Este ejemplo puede relacionarse con el primigenio llagar que se dio en las casas asturianas. Dentro del croquis que realiza para explicar cómo debería ser la configuración de dicha construcción (Fig. 2a), añade una bodega y en el texto que la describe, nombra algunos invariantes del tipo.

El autor de referencia en relación con las investigaciones sobre los llagares tradicionales en Asturias, -y persona imprescindible para la realización del trabajo de campo en el marco de

LÓPEZ ÁLVAREZ, Joaquín (ed.), De Santo Tomás y Pumarada, Fray Toribio. Arte General de Grangerías, San Esteban, Salamanca, 2006, p. 962. la presente investigación-, es Inaciu Hevia Llavona ${ }^{8}$. Realizó un dibujo sencillo (Fig. 2b), aunque acotado, -de plena utilidad para la investigación arquitectónica- del llagar de don Pedro Caravia en Gobiendes, perteneciente a Colunga.

Entre los levantamientos realizados en la obra España Dibujada ${ }^{9}$, de los hermanos Efrén y José Luis García Fernández, grandes dibujantes y documentalistas de la arquitectura tradicional, se observan algunos ejemplos de llagares asociados a vivienda (Fig. 3a). Cabe destacar que dentro de su trabajo no dibujaron estos llagares de manera intencionada, sino que aparecen, por derivada, representados formando parte de conjuntos más amplios. No se ha documentado hasta el momento ningún caso en el que dibujen un llagar exento, siempre están estos, como se ha dicho anteriormente, asociados a vivienda. No obstante, son varios los casos en los que se pueden observar

${ }_{8}$ HEVIA LLAVONA, Inaciu, Sidra y llagares tradicionales en tierras de Maliayo, Fundación José Cardín, Villaviciosa, 2011, p.56.

9 GARCÍA FERNÁNDEZ, Efrén y José Luis, España Dibujada 1. Asturias y Galicia, Servicio Central de Publicaciones del Ministerio de la Vivienda, Madrid, 1972, p. 217. 

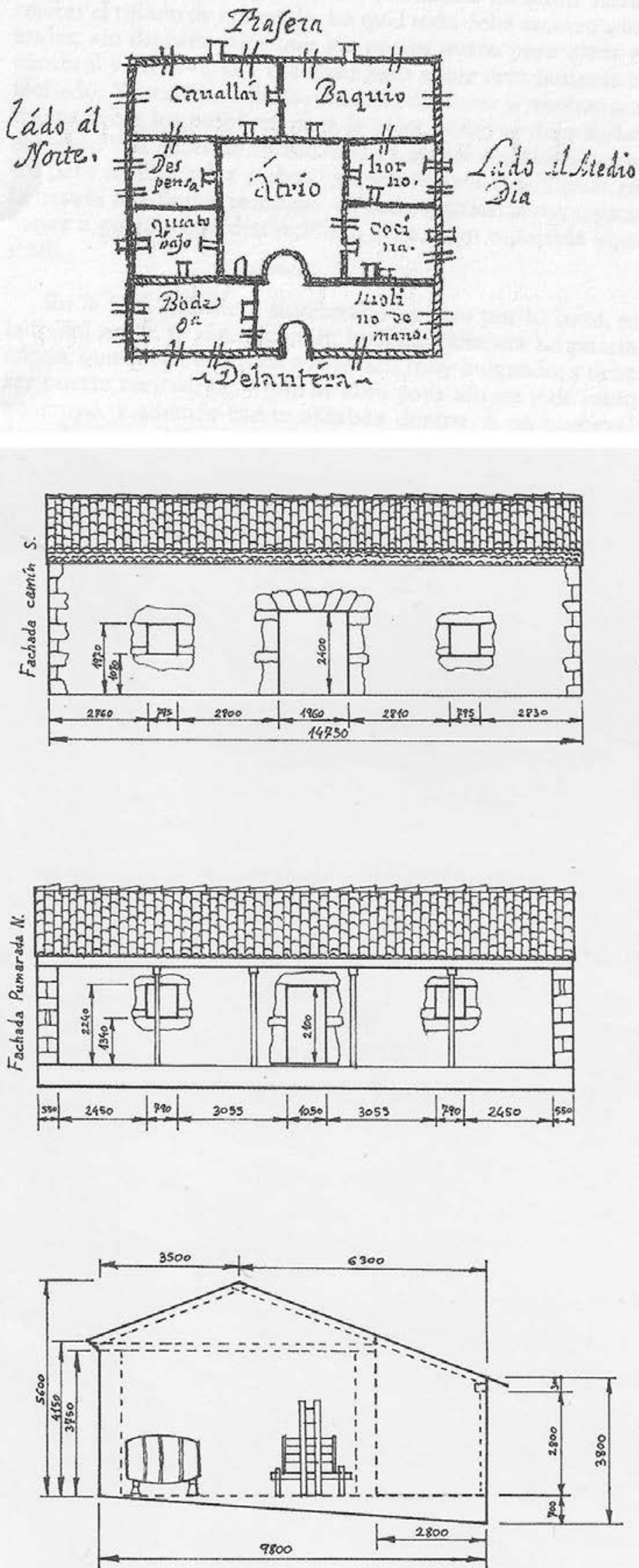

Fig. 2. Composición de imágenes de elaboración propia. Fig 2a. Croquis de vivienda con llagar asociado realizado por Fray Toribio de Santo Tomás y Pumarada en el Arte General de Gragerías (s.XVIII). Extraído de la publicación de Joaquín López Álvarez sobre la obra anteriormente citada, 2006, p.962. Fig.2b. Croquis del Llagar de Don Pedro Caravia en Gobiendes. Realizado por Inaciu Hevia Llavona. Extraído de su obra Llagares tradicionales en Tierras de Maliayo, 2011, p.56. 
entre sus dibujos publicados lo que reafirma la gran proliferación de llagares en las casas asturianas.

La más completa documentación gráfica en relación a los llagares tradicionales y, en especial, a los útiles etnográficos, es decir, los bienes muebles que forman parte indisociable del edificio, fue realizada por el dibujante José María Legazpi ${ }^{10}$. Es destacable especialmente su sección del llagar mataterrenu junto a vivienda (Fig. 3b).

Sin embargo, desde el punto de vista gráfico, en apoyo a la definición arquitectónica del llagar tradicional de sidra como tipo y realizando dibujos enfocados directamente al estudio de estas arquitecturas, con un método, grafismo y pensamiento propios del arquitecto, no se ha conseguido datar la existencia de otros documentos gráficos hasta el momento.
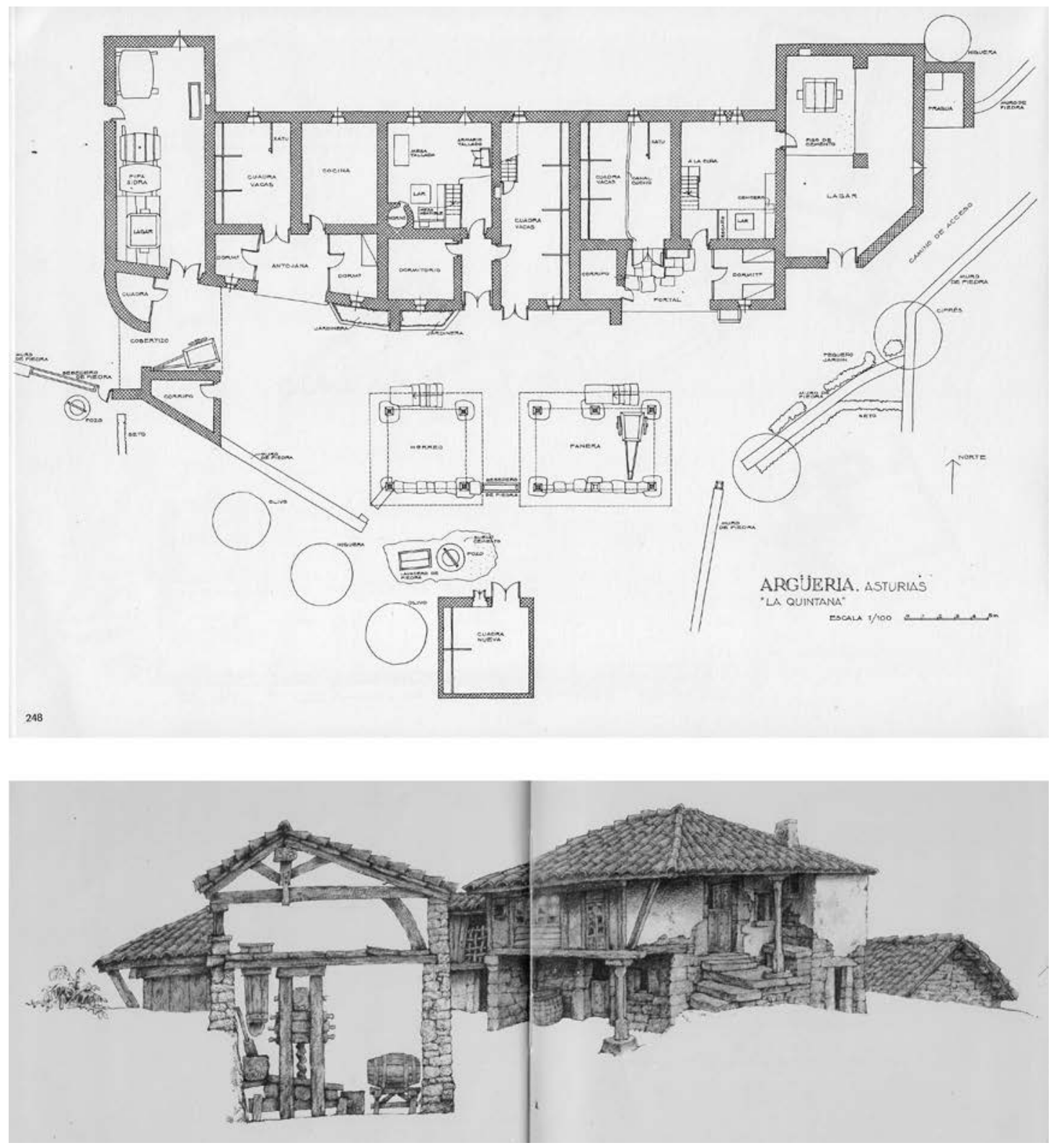

Fig. 3. Composición de imágenes de elaboración propia. Fig. 3a. Planta de una quintana con llagar asociado. Extraído de España dibujada 1. Asturias y Galicia, de Efrén y José Luis García Fernández, p.248. Fig. 3b. Sección de llagar asociado a vivienda. Extraída del libro El llagar y la sidra de José María Legazpi, 1982, pp. 12 y 13.

10 LEGAZPI, José María, El llagar y la sidra, Biblioteca Popular Asturiana, Gijón, 1982, pp. 12 y 13. 


\section{El llagar: los invariantes del tipo}

El término "invariantes" se debe al maestro Fernando Chueca Goitia. Realizaba su justificación de la elección de dicho término y no otro, del siguiente modo: "una constante, (...), es algo fijo, algo inmutable que no responde a ninguna situación ni llamada especial. (...) Al trasladar (...) a un terreno histórico, como es este de nuestra arquitectura, un concepto de persistencia de indole casi matemática, nos ha parecido, por consiguiente, mucho más adecuado usar el término invariante con toda su flexibilidad y fluidez que el de constante, cuya rigidez contraviene el vagaroso fluir del proceso histórico." 11 Puede decirse de los invariantes, por tanto, como indica Chueca Goitia, que son características que sobreviven dentro de un proceso de mutabilidad en el transcurso histórico y, a través de ellas, entre otras muchas cosas, puede definirse el tipo arquitectónico.

Los llagares tradicionales, como ocurre de manera genérica en la arquitectura vernácula, son elementos intrínseca y necesariamente relacionados con el paisaje, con el territorio y que adquieren verdadero valor al ser estudiados dentro de un conjunto. Como indicaba Carlos Flores, "la significación plástica en las obras de arquitectura popular parece acentuarse cuando se consideran éstas formando parte de amplios conjuntos" $"$.

Como podemos extraer de aquello escrito por García Grinda referido a la "definición del concepto del tipo en la arquitectura popular"; el tipo, "se clasifica (...) constatando las permanencias o relevancias comunes de un grupo completo"13, es decir, los invariantes identificados que van a configurarlo.

Para una mejor comprensión del tipo arquitectónico se decide, en este caso concreto, acompañar el texto con tres dibujos realizados por el autor en planta, sección y axonometría, que ilustran los invariantes de los que se está hablando. La planta complementa la exposición de algunos invariantes en relación con la

11 CHUECA GOITIA, Fernando, Invariantes castizos de la arquitectura española, Dossat, Madrid, 1947, p.29.

12 FLORES LÓPEZ, Carlos, Arquitectura popular española, Aguilar, Madrid, 1973, p.76.

13 GARCÍA GRINDA, José Luis, “La aplicación del tipo en la arquitectura popular: evolución versus permanencia en el territorio castellano-leonés", en Arquitectura popular de España: actas de las jornadas, 1-5 diciembre 1985, p.431-447. integración de los llagares en el territorio; y la sección, la exposición del carácter unitario entre edificio y sus bienes muebles además de una breve explicación del proceso productivo. La axonometría ayuda a la descripción de los invariantes en relación con los materiales locales, la volumetría y los sistemas constructivos de los que están compuestas estas arquitecturas.

Integración en el territorio. El llagar de sidra es un elemento indisociable del lugar en el que se encuadra, de él emana y a él se debe.

Las pomaradas, de las que se extrae la materia prima para la fabricación de la sidra: la manzana, se extienden asociadas a los llagares. Pomaradas y edificios, en conjunto, forman un paisaje muy característico de la Comarca de la Sidra.

Como se observa en la planta (Fig. 4a), el llagar arquetípico está construido mataterrenu, -contra el terreno-, excavado en el mismo y muchas veces elevado directamente sobre la roca madre, generándose el efecto cueva preciso en la fabricación de la sidra para cubrir las necesidades de humedad y temperatura constantes.

El acceso a los llagares arquetipo, -por la propia morfología del terreno en el que se integran-, se realiza generalmente desde dos cotas distintas y en orientaciones opuestas, una más baja al norte, para el acceso de carros y toneles, en relación con las vías de comunicación; $\mathrm{y}$ otra pequeña al sur, en contacto directo con la pomarada.

La orientación óptima del muro por el que se realiza el acceso principal en los llagares, mediante un portalón central, es la norte -ajena a los vientos cálidos del sur-. Esta va a permitir que las condiciones lumínicas interiores necesarias de semi penumbra se mantengan, al no tener irradiación solar directa en ningún momento del día.

La necesidad de agua es una clara invariante en los llagares tradicionales. El proceso de fabricación sidrero precisa unas condiciones de higiene constantes. Todos los elementos del llagar se lavan con mucha frecuencia e incluso en ocasiones se introduce un reguero de agua para enfriar el ambiente. En la práctica totalidad de los casos analizados en el trabajo de campo, junto a los llagares se ha identificado la existencia de un pozo, una fuente o incluso un riachuelo. No es casual, por tanto, la ubicación de los llagares junto a lugares del territorio con presencia de agua. 

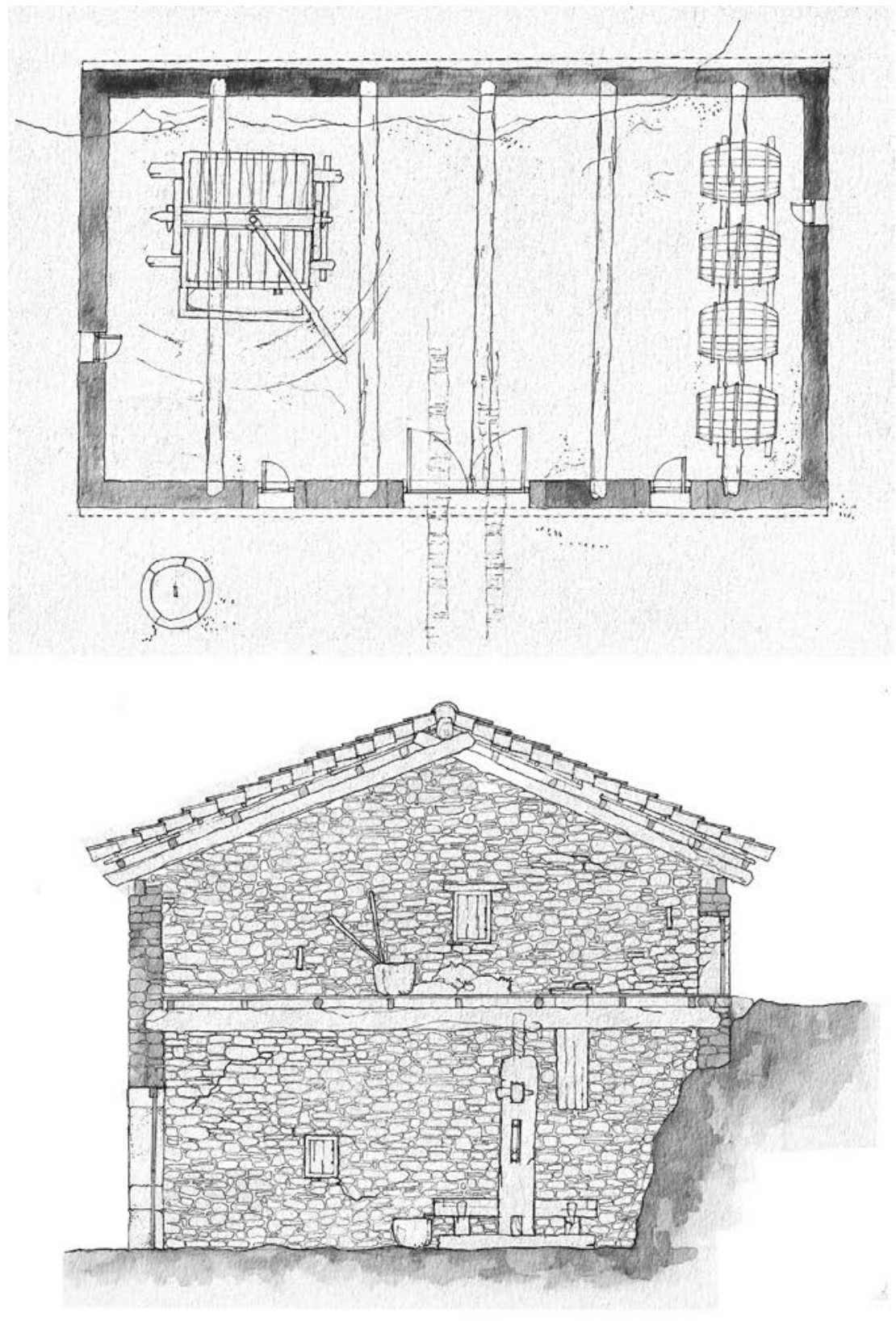

Fig 4. Composición de imágenes de elaboración propia. Fig. 4a. Planta de llagar exento de elaboración propia. Fig. 4b. Sección de llagar exento de elaboración propia.

Máquina. Si tomamos la acepción de la RAE que define "máquina" como "agregado de diversas partes ordenadas entre si y dirigidas a la formación de un todo", podemos entender el llagar como máquina. La representación del llagar desde la sección (Fig. 4b) es de utilidad para la correcta comprensión del proceso productivo, así como de la concepción del carácter unitario que presentan edificio y elementos muebles que en él se integran.

El llagar, por lo anteriormente enunciado, puede entenderse como un todo, formado por la envolvente arquitectónica y sus piezas, en- tendidas como aquellos bienes muebles y útiles que intervienen en la fabricación. El continente pierde su razón de existir si es vaciado de contenido y los elementos del llagar se descontextualizan absolutamente cuando dejan de formar parte del edificio para el que fueron concebidos. En este proceso productivo, edificio y útiles son indisociables y funcionan juntos como un todo unitario.

Dentro del proceso productivo, los elementos muebles más importantes son las prensas, también denominadas llagares. Las hay de varios tipos y tamaños y serán definitorias para la 
concepción y dimensión del espacio. Bien es el caso de las prensas de pesa o las de sobigañu que precisan ser colocadas en espacios con una altura libre bastante superior a las prensas denominadas de apretón. Generalmente las prensas de sobigañu o de pesa, precisan un espacio en doble altura para que la gran viga que las caracteriza en la acción de prensado tenga espacio de movimiento, colocándose en llagares de una sola planta o de dos plantas, pero teniendo el manzaneru retranqueado de la viga de la prensa. Las prensas de apretón son mucho menos exigentes espacialmente y aunque menos espectaculares, están muy generalizadas especialmente en llagares más evolucionados, de nuevo por economía de medios. Es importante destacar que el tamaño de estas prensas es directamente proporcional a su productividad, a mayor tamaño, mayor cantidad de litros son capaces de extraer.

De manera sucinta, la fabricación de la sidra encuentra su origen en el cultivo de la manzana. Esas manzanas se recogen en las pomaradas, próximas a los llagares. Una vez recogidas, se llevan, normalmente, al piso alto, denominado manzanenu o canigú, donde se almacenan. A este espacio se accede por una pequeña puerta en contacto directo con la pomarada, anteriormente citada, lo cual facilita y disminuye los desplazamientos de la manzana, proporcionando reducciones considerables en cuanto al tiempo y el esfuerzo físico.

Posteriormente, las manzanas se escogen, limpian y se les retiran hojas y otras impurezas antes de procederse a su mayado, (machacado) con los mayos en la duerna de mayar o, de manera evolucionada, con una mayadora, hasta producir la magaya, (masa de manzana apisonada).

Desde el piso alto, se echa la magaya en la masera de la prensa, a la que el producto desciende por gravedad. A continuación, comienza el proceso de apretado y el líquido sale por unos elementos denominados pinganexos para ser recogido en un recipiente de madera o piedra llamado duernu. Desde ahí se echa el jugo en los toneles, donde la sidra fermenta.

Resulta necesario añadir que en el proceso productivo de la sidra es imprescindible que el espacio interior de los llagares presente unas condiciones estables de temperatura y humedad a lo largo de todo el año, ya que los cambios bruscos o las temperaturas elevadas mermarían e impedirían la correcta calidad de la sidra.
Recurso de la tierra. La representación axonométrica de un llagar tipo (Fig. 5) es útil para tratar materialidad, volumetría y sistemas constructivos. Como señala el PNAT: "es importante reconocer y mantener su carácter de arquitectura directa y espontánea y, al mismo tiempo, sabia y sensata, resultado de una decantación secular del saber constructivo" ${ }^{14}$. Son arquitecturas que recurren constantemente a la economía de medios para desarrollarse.

La arquitectura tradicional sidrera está construida en piedra y madera, siendo predominantes el roble y castaño. Como indica Rivas: "no interviene en la elaboración de la sidra hierro alguno, ya que se trata de un enemigo terrible de nuestra bebida" ${ }^{15}$.

Debe considerarse el edificio como un bloque compacto con un elevadísimo predominio del macizo sobre el hueco. La envolvente se perfora de manera muy contenida, sólo lo imprescindible y necesario para iluminar y ventilar.

Los paramentos verticales son muros pétreos macizos realizados en mampostería. Se observan algunos casos que están enfoscados al exterior, no ocurriendo hacia el interior, que presenta de manera generalizada piedra vista. $\mathrm{Al}$ exterior se trabaja de manera más cuidada la piedra en los elementos esquineros y las líneas de arquitectura de los huecos. El espesor y carácter tectónico de estos paramentos es imprescindible para proporcionar inercia térmica y conservar el espacio interior en las condiciones higrotérmicas necesarias.

Los huecos mayores se encuentran en la fachada norte y están conformados por un portalón central -por el que caben los toneles e incluso un carro-, y, con mayor frecuencia, dos pequeños huecos a los lados, simétricos. Estos huecos sirven para dar luz y ventilación al espacio, cuando ésta se precisa puntualmente durante los trabajos en el interior. Suelen tener elementos de oscurecimiento de madera y con apertura desde y hacia el interior.

En las demás orientaciones los muros son prácticamente macizos. Se abren en ellos huecos mínimos por necesidades de ventilación del interior $\mathrm{y}$, normalmente, existe en la parte tra-

\footnotetext{
Plan Nacional de Arquitectura Tradicional, Ministerio de Educación Cultura y Deporte - Gobierno de España, Madrid, 2015, p.41. [https://sede.educacion.gob.es/publiventa/d/20699C/19/1]

15 RIVAS, David, La sidra asturiana. Bebida, ritual y simbolo, Picu Urriellu, Gijón, 2004, p.102.
} 


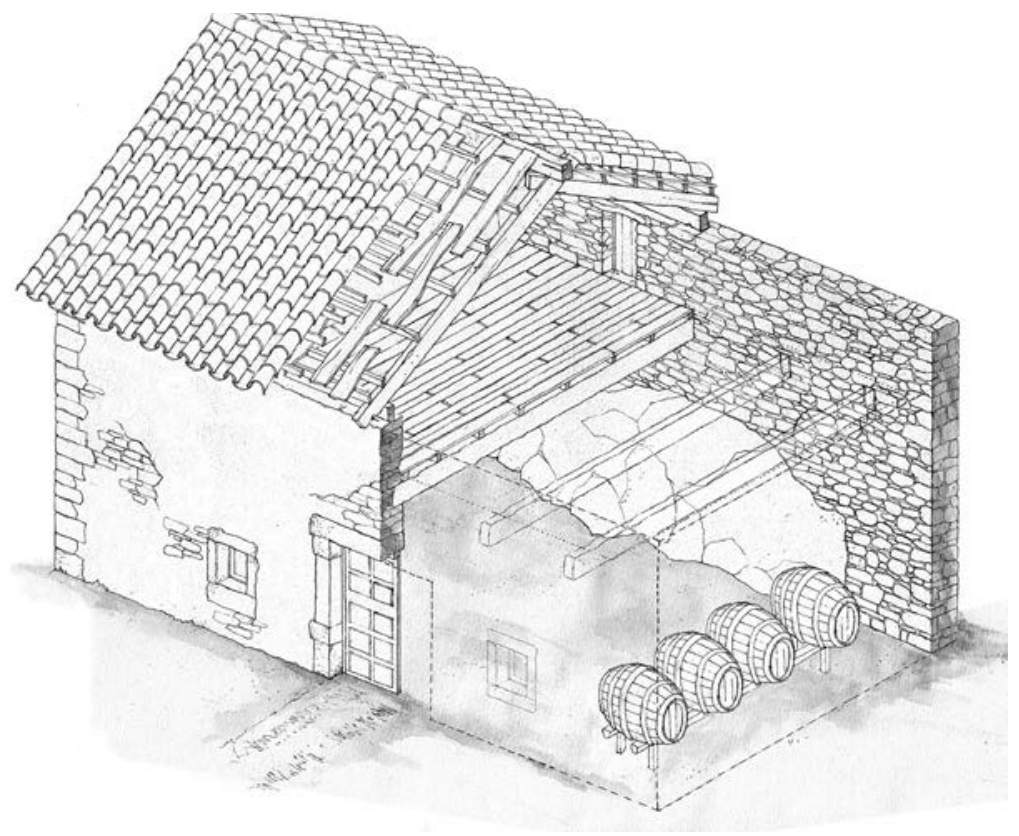

sera o en una de las fachadas laterales una pequeña puerta cuya función, como ya se ha indicado, es la introducción de las manzanas en el edificio por el piso elevado desde la pomarada.

Otro elemento fundamental en el llagar en relación con la ventilación es la cubierta. El aire caliente asciende y es correcto admitir que los llagares "respiran por la cubierta", ya que estas se construyen a teyavana (con ripias sobre las que se colocan directamente las tejas) y apoyadas sobre los muros de manera rudimentaria, lo que permite la existencia de huecos de ventilación en la coronación de los muros. No hay ningún elemento de aislamiento en la cubierta que la convierta en un continuo sólido que no transpira. Por ello, la visión que se percibe de las cubiertas desde el interior arquitectónico, es un complejo desordenado de madera y teja, interrumpido por ligeros haces de luz del exterior, que hacen inconfundible la sensación onírica de encontrarse dentro de un llagar.

Estas cubiertas presentan armaduras de madera variables en los distintos ejemplos estudiados. Se encuentran llagares a un (Fig.1a), dos y cuatro aguas, predominando los casos con cubiertas a dos aguas. En la práctica totalidad de los casos tratados, los faldones son paralelos a la fachada principal. Estas cubiertas se articularán en función del espacio interior a cubrir, buscando la simplicidad constructiva, sin alardes y salvando luces lo más pequeñas posibles, aprovechando la madera local disponible.
El pavimento interior es generalmente de tierra apisonada, el terreno original. Esto tiene una clara intención funcional, ya que además de la economía de medios, es un suelo que drena de manera natural, algo imprescindible en un proceso productivo donde agua y sidra son dos elementos en constante presencia.

La dimensión del edificio dependerá de diversas razones, tales como el nivel económico de sus propietarios o la necesidad productiva del mismo. Como se ha indicado anteriormente, las prensas tendrán una relación directa con la configuración espacial y volumétrica del edificio, según sea su tamaño en función de la necesidad de generar mayor o menor cantidad de sidra.

\section{Adaptaciones del tipo}

Se han expuesto las invariantes de un tipo genérico de llagar tradicional de sidra asturiano, pero, como resulta natural -especialmente en el campo de la arquitectura vernácula-, a partir de éste pueden exponerse interesantes variantes.

Estas arquitecturas forman parte de un patrimonio de carácter material, pero son muchas las características de carácter inmaterial que lo hacen existir, evolucionar o experimentar modificaciones más o menos sustanciales (como por ejemplo la transmisión oral de las tradiciones o los cambios en los modos de vida), aun- 
que el carácter productivo primigenio de estos edificios se mantenga inalterable.

Es fundamental en el estudio de estas construcciones -y su evolución- no caer en el error de intentar situarlas en una delimitada dimensión cronológica acotada, ya que no responden a un tiempo exacto ni a un estilo. Son arquitecturas atemporales en las que, sin embargo, debe significarse una evolución en las necesidades productivas y funcionales. Más que el factor tiempo, son los valores del paisaje y la producción los que deben barajarse como modificadores paulatinos de los invariantes.

La principal diferenciación de las mismas es su configuración volumétrica y su relación con el entorno, que tiene el origen claro en la producción de sidra sólo para consumo familiar (en los primitivos) o también para la venta y distribución, como fuente importante de la economía doméstica (en los más evolucionados).

Primigenio. Se contempla la hipótesis de que el antecedente del llagar exento mataterrenu arquetipo puede buscarse en el primigenio. Éste se considera asociado al hogar, en la orientación sombría del norte y que surgió en un contexto de economía de subsistencia. En la vivienda eran necesarios ciertos animales para la alimentación diaria o para la ayuda en el trabajo del campo. Del mismo modo, en estos lugares de Asturias existía, algunas veces, un pequeño campo de pomar del que se extraía, tras su proceso de fabricación en los llagares, la sidra para beber, como consumo doméstico. No existían aún los sistemas de saneamiento generalizados, era un contexto rural muy modesto. Se estima que esos primeros llagares, podrían además tener uso mixto como almacenes o tareas diversas vinculadas al núcleo del hogar.

Exento. Se considera el llagar arquetipo descritos sus invariantes en profundidad anteriormente- como aquel en mitad de una pomarada o al fondo de una pequeña agrupación de casas, aislado, surgiendo del terreno, en el límite de dicha pomarada con el pueblo. Estas construcciones solían tener un propietario particular, pero todo el pueblo se vinculaba al proceso productivo sidrero, trabajando en andecha. "Pagaban" con mano de obra productiva la posibilidad de disfrutar posteriormente del consumo particular de la sidra.

En hilera. Puede ser o no ser mataterrenu y muchas veces posee una sola planta, suele estar asociado a un chigre, -especie de bar donde se vende sidra-, y situado junto a vías de comuni- cación. Estos llagares proliferaron cuando la sidra trascendió del único consumo doméstico y pasó a ser vendida y considerarse un recurso económico dentro de la economía de las familias.

En Palacios o casonas asturianas. Existen también grandes llagares que forman parte de Palacios o Casonas, algunos incluso poseen asociada la casa del llagarero, que pertenecía al servicio de la casa.

Llagar mariñán. Se da en la zona de Las Mariñas de Villaviciosa. Pertenece al conjunto de las Casas Mariñanas, una tipología edificatoria específica de este territorio formada por: vivienda, cuadra y llagar. Estos llagares tiene planta baja y manzaneru, se adosaban a la vivienda por un lateral y se utilizaban tanto para el consumo doméstico o para la venta, lo cual alteraba sus dimensiones.

\section{Conclusiones}

El dibujo arquitectónico en relación con los llagares tradicionales de sidra es casi inexistente por lo que la ampliación del estado de la cuestión en este sentido es una aportación original muy útil en términos de documentación y difusión.

Los llagares de sidra tradicionales son un tipo arquitectónico actualmente en peligro de desaparición. La principal causa se encuentra en la evolución de estas arquitecturas hacia un proceso productivo industrializado, en el que priman la velocidad del mismo y los rendimientos económicos. Por otra parte, cabe destacar la generalizada desprotección de estos edificios. Los mejor conservados son aquellos que mantienen el uso para consumo propio por familias que perpetúan las tradiciones no por necesidad de su economía doméstica, sino como medio de sociabilidad.

Otro aporte a tener en cuenta es la definición del tipo en relación a los condicionantes constructivos, productivos, geográficos y topográficos, así como de la determinación de la evolución de aspectos sociales y antropológicos del pasado hasta la situación actual.

La aproximación tanto textual como gráfica al llagar tradicional, constituye una investigación no tratada anteriormente desde el ámbito competencial del arquitecto. Es fundamental el estudio, conocimiento y divulgación como vehículo de concienciación para la preservación de este patrimonio basado en la sinceridad constructiva. 